\title{
Laparoscopic high anterior resection for unicentric Castleman's disease of the sigmoid mesocolon
}

Short Title: Lap HAR for CD of sigmoid mesocolon

Authors:

Jordan M Hamilton MBBS, MTrauma

Hussain Al Khdhur MBBS, SB-SURG

Catherine Mitchell MBBS, FRCPA

Satish K Warrier MBBS, MS, FRACS

Alexander G Heriot MB, BChir, MA, MD, MBA, FRACS, FRCS(Gen.), FRCSEd, FACS, GAICD

Institution: Division of Cancer Surgery, Peter MacCallum Cancer Centre, Victorian Comprehensive Cancer Centre, Melbourne, Victoria, Australia.

Declaration: There are no conflicts of interest to declare and no funding was required for this project. The corresponding author is not the recipient of any research scholarships, this manuscript is not based on any previous communication or publication.

Word count: 720

Number of figures: 2

Corresponding Author:

Jordan M Hamilton

Email: jordan.m.hamilton@gmail.com

Postal address: 9 Amelia Street, Brunswick Victoria, 3056.

Phone: +61421315697

This is the author manuscript accepted for publication and has undergone full peer review but has not been through the copyediting, typesetting, pagination and proofreading process, which may lead to differences between this version and the Version of Record. Please cite this article as doi: 10.1111/ans.15792

This article is protected by copyright. All rights reserved. 
Castleman's Disease $(C D)$ is a rare yet benign cause of intra-abdominal lymphadenopathy that may be difficult to differentiate pre-operatively from intra-abdominal lymphomas or other enteric neoplasms ${ }^{1}$. In these settings the mainstay of curative management is complete surgical excision with clear margins, which carries an exceedingly low recurrence rate. Historically, methods of resection for intra-abdominal CD have varied, due both to the exceedingly rare nature of the condition as well as its highly variable location of presentation. To date, minimally invasive resection of mesenteric $C D$ has been uncommon however where practical, it may provide a safe alternative to open surgery.

A 68 year old female was found to have a $3 \mathrm{~cm}$ mass in the sigmoid mesocolon on ultrasound to investigate pelvic discomfort. Confirmatory computed tomography (CT) scan showed a uniform, well circumscribed $3 \mathrm{~cm}$ mass in the sigmoid mesocolon with a number of smaller, sub-centimetre lymph nodes seen along the superior and inferior mesenteric arteries (Figure 1). These features were deemed concerning for a possible intra-abdominal lymphoma or gastro-intestinal stromal tumour (GIST).

The patient underwent a normal colonoscopy followed by a fluorodeoxyglucose positron emission tomography (FDG PET) scan. This showed only mild to moderate tracer uptake in the sigmoid mesenteric mass with features concerning for a sarcoma or GIST with a differential diagnosis of low-grade lymphoma (Figure 1).

After multidisciplinary discussion, the patient was planned for a laparoscopic biopsy of the sigmoid mesenteric mass. Laparoscopy revealed a $3 \times 3 \mathrm{~cm}$ mass contained within the sigmoid 
mesocolon which was not amenable to removal without formal resection. The patient underwent an uncomplicated laparoscopic high anterior resection. Their postoperative course was uncomplicated and they were discharged home on the fourth post-operative day.

Histopathology of the excised specimen demonstrated a $31 \times 30 \times 23 \mathrm{~mm}$ homogenous pale tan fleshy mass within the sigmoid mesentery, located $20 \mathrm{~mm}$ from the colonic wall. Microscopic evaluation of the mass showed a mass of lymphoid tissue, containing multiple variably sized follicles, with expanded follicular dendritic cell meshworks (demonstrated with CD21 immunohistochemistry). These follicles contained one, or sometimes two atrophic germinal centres (reactive for CD10 and bcl-6, but negative for bcl-2), and displayed expanded mantle zones showing concentric rimming or "onion-skinning" of lymphocytes. There were prominent small blood vessels in interfollicular zones and sometimes extending radially into the follicles. Overall, the features were in keeping with hyaline-vascular Castleman's disease ${ }^{2}$ (Figure 2). Immunohistochemistry for HHV-8 was negative. The large intestinal mucosa and twelve lymph nodes retrieved from the specimen were unremarkable. The mass was well clear of the margins of surgical resection.

Castleman's disease is a rare lymphoproliferative disorder originally described by Benjamin Castleman, a pathologist at Massachusetts General Hospital in $1954^{3}$. Although it may arise in any lymphatic tissue, $C D$ is most commonly found in mediastinal lymph nodes with other 
locations such as the neck, abdomen and axilla all described less commonly. It may be classified into 3 histological subtypes, a hyaline-vascular type, a plasma cell based type and a mixed variant ${ }^{1}$. The disease may further be classified as unicentric or multicentric as defined by the number of lymph nodes involved. Intra-abdominal CD arising from mesenteric structures is a rarity, with only 57 cases described in the literature to date ${ }^{1,4,5}$. Cases arising from the sigmoid mesocolon, such as in this case are particularly rare, with only five cases previous described ${ }^{6,7,8,9}$. In these previous examples, the $C D$ was most frequently of the unicentric and hyaline vascular forms. This was also the case for the patient described above. Previous cases of mesenteric CD have indicated that complete surgical resection of unicentric $C D$ is usually curative and carries an exceedingly low recurrence rate ${ }^{3}$. All previous cases of sigmoid mesenteric CD have been managed with open resection. To the best of the authors' knowledge this is the first case of CD of the sigmoid mesocolon managed laparoscopically described in the literature. For this patient, a laparoscopic approach proved to be a safe, minimally invasive option whilst still achieving clear margins of surgical resection.

Although rare, Castleman's Disease should be considered in the differential diagnosis of intra-abdominal lymphadenopathy and may mimic other lymphoproliferative disorders or neoplasms of the bowel. Accurate pre-operative diagnosis remains difficult and complete excision with clear surgical margins is integral to achieving curative resection. Depending

This article is protected by copyright. All rights reserved. 
upon the location of the lesion and other patient related factors, this may safely be achieved via minimally invasive methods as demonstrated by this case.

\section{$\underline{\text { References }}$}

1. Bracale U, Pacelli F, Milone M, Sodo M, Merola G, Troiani T, Di Salvo E. Laparoscopic treatment of abdominal unicentric castleman's disease: a case report and literature review. BMC Surg. 2017; 17: 38

2. Jongsma TE, Verburg RJ, Geelhoed-Duijvestijn PH. Castleman's disease: A rare lymphoproliferative disorder. Eur. J. Intern. Med. 2007; 18: 87-89

This article is protected by copyright. All rights reserved. 
3. Castleman B, Towne VW. CASE records of the Massachusetts General Hospital: Case No. 40231. N. Engl. J. Med. 1954; 250: 1001-1005.

4. Ozsoy M, Ozsoy Z, Sahin S, Arikan Y. Rare forms of castleman disease mimicking malignancy: Mesenteric and pancreatic involvement. Cureus. 2018; 10: e2310

5. Bhogal RH, Wotherspoon A, Khan AK. Mesenteric castleman's diseas mimicking neuroendocrine tumour. Int. J. Surg. Case Rep. 2019; 63: 56-58

6. Testas P, Pigne A, Voinnesson A. Angiofollicular lymphoid hyperplasia (Castleman's disease). First case of meso-sigmoid localisation. J. Chir. 1980; 106: 156-160

7. MacDonald SR, Lurain JR, Hoff F, Variakojis D, Fishman DA. Castleman disease presenting as a pelvic mass. Obstet. Gynecol. 1996; 87: 875-877

8. Altinli E, Pekmezci S, Balkan T, Somay A, Buyukbese MA, Tasci H, Akcal T. Castleman's disease masquerading as sigmoid colon tumour and Hodgkin lymphoma. Swiss Surg. 2002; 8: 7-10

9. Katayama N, Kohno Y, Morita H, Nakagawa T, Sonobe H, Kanazawa S. A case of castleman's disease of the sigmoid mesocolon. JPN J. Radiol. 2005; 50: 1071-1075

This article is protected by copyright. All rights reserved. 


\section{Figure Legends}

Figure 1. Pre-operative computed tomography view in (a) axial and (b) coronal planes of sigmoid mesenteric mass (red arrows). (c) FDG PET imaging demonstrating mild to moderate FDG uptake.

This article is protected by copyright. All rights reserved. 
Figure 2. Histological sections of excised sigmoid mesenteric mass. (a) haematoxylin and eosin (H\&E) stained section at 20x magnification showing multiple enlarged follicles. (b) Immunohistochemistry for CD21 at 20x magnification showing expanded follicular dendritic meshworks. (c) H\&E at 100x magnification showing follicle with atrophic germinal centre, expanded mantle zone with "concentric rimming" of lymphocytes and blood vessels with hyalinised walls.

This article is protected by copyright. All rights reserved. 


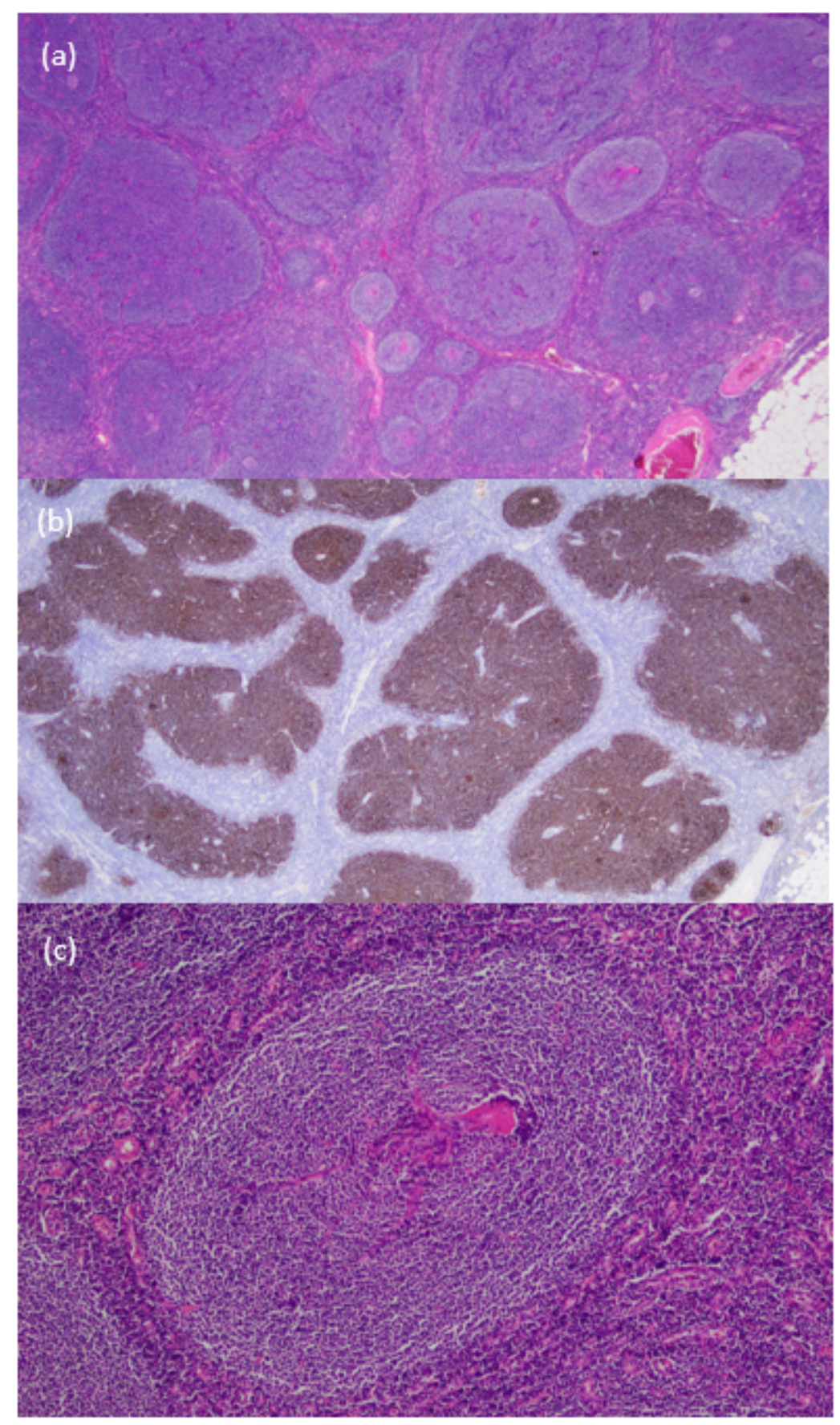

ANS_15792_Figure 2. microslides tiff.tiff

This article is protected by copyright. All rights reserved. 


\section{University Library}

\section{- M M N E R VA A gateway to Melbourne's research publications}

Minerva Access is the Institutional Repository of The University of Melbourne

Author/s:

Hamilton, JM;Al Khdhur, H;Mitchell, C;Warrier, SK;Heriot, AG

Title:

Laparoscopic high anterior resection for unicentric Castleman's disease of the sigmoid mesocolon

Date:

2020-03-02

Citation:

Hamilton, J. M., Al Khdhur, H., Mitchell, C., Warrier, S. K. \& Heriot, A. G. (2020).

Laparoscopic high anterior resection for unicentric Castleman's disease of the sigmoid

mesocolon. ANZ JOURNAL OF SURGERY, 90 (10), pp.2137-2138. https://doi.org/10.1111/ ans. 15792.

Persistent Link:

http://hdl.handle.net/11343/275500 